\title{
Drug-Induced Erythrocyte Membrane Internalization
}

\author{
Isaac Ben-Bassat, Klaus G. Bensch, and Stanley L. Schrier \\ From the Departments of Medicine and Pathology, Stanford University \\ School of Medicine, Stanford, California 94305
}

A B S T R A C T In vitro erythrocyte membrane internalization, resulting in the formation of membrane-lined vacuoles, can be quantified by a radioisotopic method. A complex of ${ }^{57} \mathrm{Co}$-labeled vitamin $\mathrm{B}_{12}$ and its plasma protein binders is first adsorbed to the cell surface, and after vacuoles are formed, the noninternalized label is removed by washing and trypsin treatment. The residual radioactivity represents trapped label and can be used to measure the extent of membrane internalization.

Using this method, it was found that in addition to primaquine, a group of membrane-active drugs, specifically hydrocortisone, vinblastine, and chlorpromazine can induce membrane internalization in erythrocytes. This is a metabolic process dependent on drug concentration, temperature, and $\mathrm{pH}$. Vacuole formation by all agents tested can be blocked by prior depletion of endogenous substrates or by poisoning the erythrocytes with sodium fluoride and sulfhydryl blocking agents. This phenomenon resembles in some respects the previously reported membrane internalization of energized erythrocyte ghosts. It is suggested that membrane internalization is dependent on an ATP-energized state and is influenced by the balance between the concentrations of magnesium and calcium in the membrane. This study provides a basis for proposing a unifying concept of the action of some membrane-active drugs, and for considering the role of erythrocyte membrane internalization in pathophysiologic events.

\section{INTRODUCTION}

A final common path in red cell aging and hemolytic disease is thought to be a modification of the membrane which is detectable by the reticuloendothelial system

Dr. Ben-Bassat was an International Postdoctoral Research Fellow of the National Institutes of Health No. 5 for F05 TW 1508-02 and was also supported by the Tommy Prescott Fund. His permanent address is Department of Hematology, The Chaim Sheba Medical Center, Tel Hashomer, Israel.

Received for publication 10 November 1971 and in revised form 19 January 1972.
(1-3). The red cell membrane has a remarkable capacity for elastic deformability, and alteration of this property has been implicated in red cell destruction $(3,4)$. Studies on red cell shape and deformability have supported the idea of the dependence of membrane fluidity on the maintenance of active metabolism (5-9). Another modality of plasma membrane function, which also appears to reflect its plastic properties, is the phenomenon of endocytosis. One form of endocytosis is the pinocytotic vacuoles which have been shown to occur in newborn red cells coated by antibodies $(10,11)$. Vacuoles in circulating cells are also frequently found in newborn cells (12) and in the postsplenectomy state, where they have been called postsplenectomy vacuoles (13) and autophagic vacuoles (14). Holroyde and Gardner (15) found that these vacuoles were acquired by normal mature erythrocytes transfused into an asplenic recipient, thereby suggesting that vacuoles are formed normally and are removed as a physiological process by a functioning spleen. While it is likely the vacuole formation in adult erythrocytes predominantly proceeds via membrane internalization, definitive data are not yet available.

Recently Ginn, Hochstein, and Trump (16) reported that incubation of normal human erythrocytes with the 8-aminoquinoline drug, primaquine, results in the formation of intracellular vacuoles by a process of membrane internalization.

Previously, observations on in vitro vacuole formation in red cells were limited either to morphologic studies or to measurements of the changes in the osmotic fragility of the red cells. These assay methods are at best semiquantitative and not suitable for kinetic measurements.

As membrane internalization seems to be a biologically important phenomenon, we decided to study the requirements and alterations of drug-mediated vacuole formation in erythrocytes. A quantitative radioactive membranelabeling method was devised and applied for measuring the extent of membrane internalization. Using this method, we established that a group of membrane-active drugs have the capacity to induce vacuole formation by a 
process of membrane internalization. Vacuole formation by all membrane-active drugs was found to be energy-requiring and could be impaired by prior substrate depletion, glycolytic inhibition, and sulfhydryl blockade.

From our observations a unifying hypothesis for the action of such drugs is proposed based on the interaction of calcium, magnesium, and ATP with the erythrocyte membrane. Furthermore, it is suggested that membrane internalization may explain events involving in vivo erythrocyte aging and destruction.

\section{METHODS}

Principle of method. In order for a specific label to be useful in studies of membrane internalization, it has to meet the following criteria: the label must bind firmly to the membrane without penetrating into the interior of the erythrocyte, and subsequently the label not trapped in internalized vacuoles must be susceptible to easy removal by washing or proteolytic digestion. Preferably, the label should be a $\gamma$-emitting isotope of high specific activity. After preliminary studies, we found that the serum-mediated vitamin $\mathrm{B}_{13}\left(\mathrm{~B}_{12}\right)$ uptake by erythrocytes as described by Retief, Gottlieb, and Herbert (17) fulfilled these requirements and could be applied to our purposes. As shown by these workers, $\mathrm{B}_{12}$ complexed to the serum-binding proteins will adsorb to receptors on the surface of red cells through a calciumdependent adsorption phenomenon. This membrane-bound $\mathrm{B}_{12}$-protein complex can be completely eluted by saline washings and trypsin digestion (17). Once the label has been internalized by the formation of vacuoles it should become inaccessible to elution. If this is the case, residual radioactivity will represent trapped label and serve as an accurate measurement of vacuole formation. Assuming that this sequence could be validated, the following procedure was adopted.

Procedures. Normal donor blood, either defibrinated or heparinized, was used throughout. The plasma, or the serum, was separated by centrifugation, the buffy coat removed as completely as possible, and the erythrocytes washed two times with 5 vol of Hanks's balanced salt solution. The separated plasma or serum was incubated at room temperature for $15-30 \mathrm{~min}$ with a subsaturating dose of $\mathrm{B}_{12^{-}}{ }^{57} \mathrm{Co}$ (cyanocobalamin- ${ }^{57} \mathrm{Co}$ aqueous solution, $\mathrm{SA} 112-122 \mu \mathrm{Ci} / \mu \mathrm{g}$ Amersham/Searle Corp., Arlington Heights, Ill.). 1 ng $\mathrm{B}_{12}{ }^{57} \mathrm{Co}$ per $\mathrm{ml}$ plasma was used. The labeled plasma was added to a $50 \%$ red cell suspension so that the final packed cell volume was $30 \%$. The cells, buffer, $\mathrm{B}_{12^{-}}{ }^{57} \mathrm{Co}$ plasma mixture were then incubated for $30 \mathrm{~min}$ at $37^{\circ} \mathrm{C}$ in order to bind the $\mathrm{B}_{12^{-}}{ }^{57} \mathrm{Co}$ protein complex to the cell surface. Whenever inhibitors or other agents were tested, they were preincubated with the cell mixture after the binding of the $\mathrm{B}_{12}{ }^{57} \mathrm{Co}$ protein complex and before the addition of the vacuole-inducing agent. The vacuole-inducing agents were added to duplicate portions of the cell suspension and further incubated at $37^{\circ} \mathrm{C}$ for varying time periods with agitation. When incubated in air atmosphere, the $\mathrm{pH}$ of the reaction mixture rose from the initial value of 7.5 to about 7.8 at the end of $2 \mathrm{hr}$ incubation. Whenever strict $\mathrm{pH}$ maintenance was required, the reaction mixture was incubated in a Dubnoff metabolic shaking incubator with an atmosphere of $5 \%$ $\mathrm{CO}_{3} 95 \%$ air.
At the end of the incubation, the treated and the control cells were washed three times with 5 vol of physiologic saline and then incubated with 5 vol of trypsin solution, $1 \mathrm{mg} / \mathrm{ml}$ at $37^{\circ} \mathrm{C}$ for $30 \mathrm{~min}$. The cells were further washed three to four times with physiologic saline, carefully removing tiny gelatinous clots which sometimes formed. The erythrocyte pellets were suspended in equal volumes of physiologic saline and the radioactivity was measured in an automatic well-type scintillation counter (Nuclear-Chicago Corporation, Des Plaines, Ill., counting efficiency 40\%). The results are expressed as counts per minute per milliliter packed red cells.

As a measure of the extent of binding of the $\mathrm{B}_{12^{-}}{ }^{57} \mathrm{Co}$ protein complex to the red cell surface, in all experiments an identical sample was carried through the incubation, washed three times with saline, but not treated with trypsin, and the radioactivity was then measured.

For studying the effects of nonionic media or nonpenetrating electrolytes on vacuole formation, the saline-washed cells were further washed three times with $0.3 \mathrm{M}$ sucrose containing $5 \mathrm{~mm} \mathrm{CaCl}_{2}, \mathrm{pH}$ 7.4. Normal $\mathrm{AB}$ type serum, extensively dialyzed against distilled water, was used instead of the autologous plasma. The nonionic or nonpenetrating materials were added in aqueous solution so that finally all reactions were iso-osmotic. Calcium chloride in a final concentration of $2.5 \mathrm{~mm}$ and glucose in a final concentration of $15 \mathrm{~mm}$ were also present. After the $\mathrm{pH}$ was adjusted with Tris- $\mathrm{HCl}$, the procedure was carried out as usual.

Sealed ghosts. For preparation of partially hemolyzed sealed ghosts (18), the following procedure was used: 1 vol of washed packed cells was hemolyzed by $10 \mathrm{vol}$ of $10 \mathrm{~mm}$ $\mathrm{Na}$-ATP $\mathrm{pH} 7.2,30 \mathrm{mOsm} / \mathrm{kg} \mathrm{H} \mathrm{H}_{2} \mathrm{O}$ for $10 \mathrm{~min}$ at room temperature. Then isotonicity was restored by adding a concentrated salt solution so that the final salt concentrations were: $154 \mathrm{~mm} \mathrm{KCl}, 10 \mathrm{mM} \mathrm{MgCl}_{2}, 2.5 \mathrm{mM} \mathrm{CaCl}_{2}$. The partially hemolyzed ghosts were incubated at $37^{\circ} \mathrm{C}$ for $30 \mathrm{~min}$ and washed once with Hanks's balanced salt solution. The sealed ghosts were then suspended in equal volume of Hanks's and further treated as the whole red cell preparations using, however, $5,000 \mathrm{~g}$ centrifugations for the washings. All other hemolyzing solutions used were adjusted to $30 \mathrm{mOsm} / \mathrm{kg} \mathrm{H}_{2} \mathrm{O}$.

ATP and reduced glutathione (GSH) determinations. ATP was determined by NADP-coupled reaction on neutralized trichloroacetic acid extracts of erythrocytes (19). GSH levels of washed cells were determined by the $5,5^{\prime}$ dithiobis-(2-nitrobenzoic acid) method (20).

Phase microscopy. Vacuole formation was monitored in a phase contrast microscope at $\times 400$ and $\times 1000$ magnification by examining the cells suspended in a hypotonic solution. When a drop of the cell suspension was mixed with a drop of distilled water on the microscopic slide, vacuoles could easily be seen in the smooth, swollen, partially hemolyzed cells. The vacuoles seen were approximate 1-3 $\mu$ in diameter, usually single or twin, empty spheres adhering to the inside of the membrane. The vacuoles could easily be distinguished from the smaller, denser, and refractile Heinz bodies which sometimes were also present. The phase contrast microscopy appearance was examined by two independent observers and, using a semiquantitative scale, was correlated to the measurements of the radioactive trapping.

Electron microscopy. For the electron microscopic studies, cells treated with primaquine, $2 \mathrm{~mm}$ for $2 \mathrm{hr}$ at $37^{\circ} \mathrm{C}$, were used. Fixation of the cells was accomplished by mixing equal volumes of the cell suspension with $2 \%$ buffered glutaralde- 


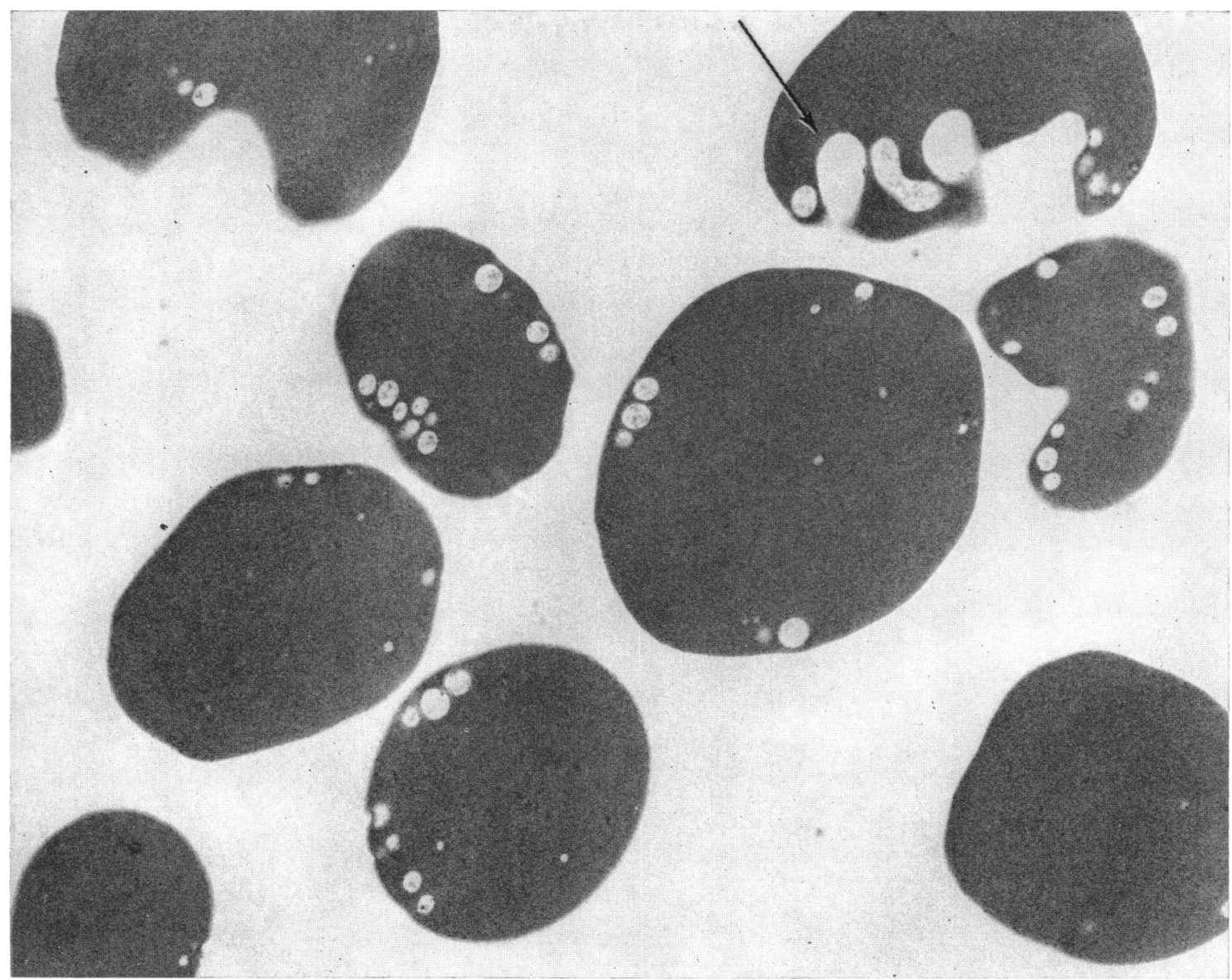

FIGURE 1 Low-power magnification electron micrograph of primaquine-treated erythrocytes. Relatively uniform-sized vacuoles confined to the cell periphery are seen. Coarse cup-shaped invaginations of the cell membrane can be seen in the cells at the right upper corner (arrow). Magnification $\times 8500$.

hyde, and after centrifugation, overlaying the pellet with more of the fixative (21). The sample, after a brief rinse in phosphate buffer, postfixation in $1 \%$ osmium tetroxide, and dehydration, were embedded in epoxy resin (Maraglas, Polysciences, Inc., Rydal, Pa.) (22, 23). $1 \mu$ sections were stained with Mallory's Azur II-methylene blue, and appropriate blocks selected for thin sectioning on an LKB (LKB Instruments, Inc., Rockville, Md.) ultramicrotome. The sections were double-stained with uranyl acetate and lead citrate (24) and examined with a Siemens Elmiskop 101 electron microscope (Siemens Corp., Iselin, N. J.).

Materials. All water soluble materials were dissolved in saline and neutralized when necessary. Some water insoluble materials were added as ethanolic solutions. All concentrations of vacuole-inducing agents, as well as inhibitors were expressed as moles per liter of the final mixture volume. The 8-aminoquinoline analogs were generously supplied by the Medicinal Chemistry Division, Walter Reed Army Institute of Research, primaquine diphosphate by Parke, Davis \& Co., Detroit, Mich., vinblastine sulfate by Eli Lilly \& Co., Indianapolis, Ind., chlorpromazine hydrochloride by Smith Kline \& French Laboratories, Philadelphia, Pa. Hydrocortisone-21-sodium succinate was obtained through Sigma
Chemical Co., St. Louis, Mo., and trypsin, $2 \times$ crystalline salt-free from Nutritional Biochemicals Corporation, Cleveland, Ohio.

\section{RESULTS}

Electron microscopy of primaquine-induced vacuoles. The morphologic appearance of the primaquine-induced vacuoles as seen by electron microscopy are shown in Figs. 1 and 2. The erythrocytes contained, as shown previously by Ginn et al. (16), large numbers of discrete vacuoles of relatively uniform size and shape, averaging $0.25-0.3 \mu$ in diameter. The vacuoles were always in juxtaplasmalemmal position and coarse cupshaped deformities were also commonly seen. (Fig. 1). After primaquine incubation in some experiments, the cells were partially hemolyzed in order to obtain sharper visualization of the erythrocyte plasma membrane. In these primaquine-treated partially hemolyzed cells, plasma membrane internalization could be actually seen 


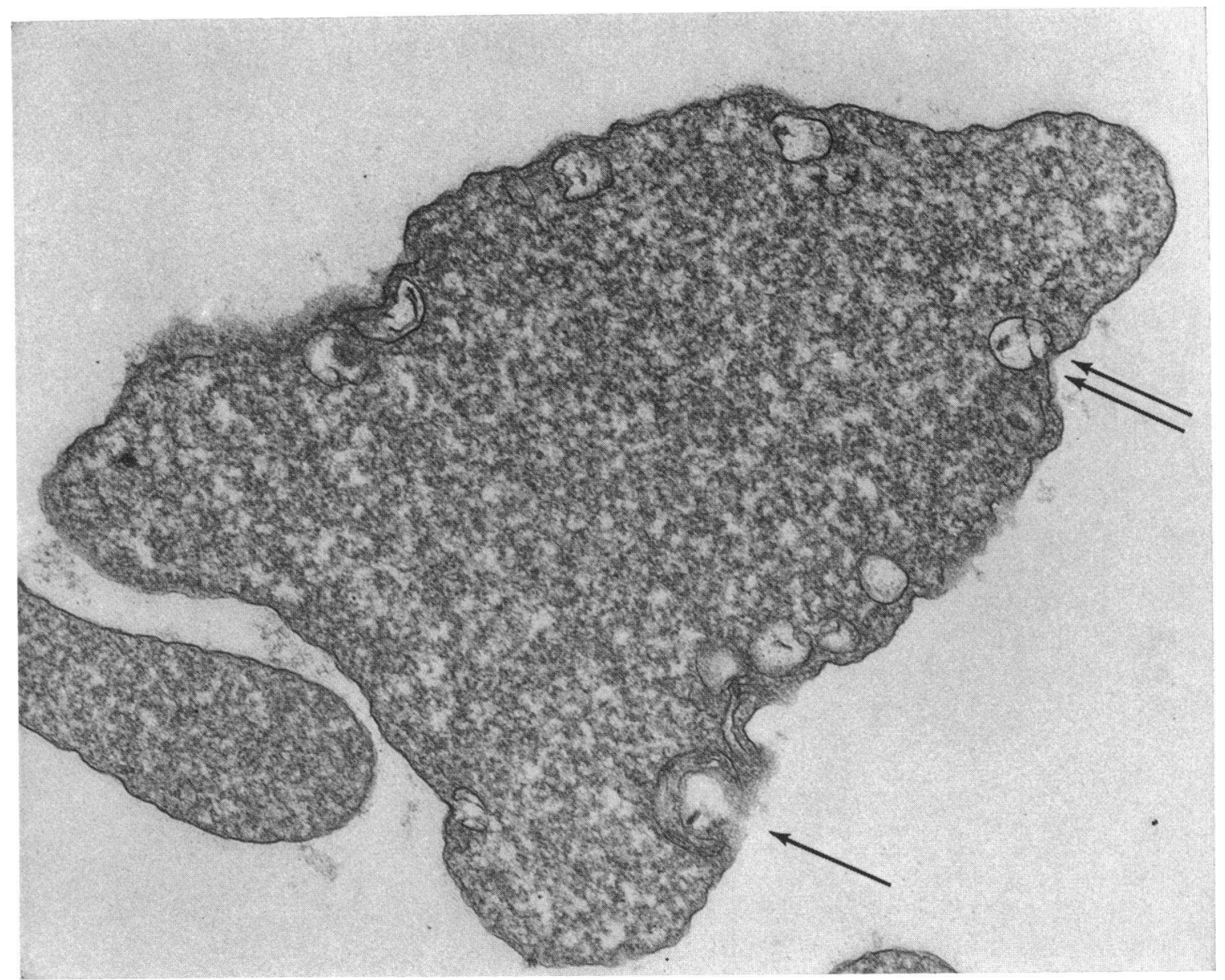

FIGURE 2 Electron micrograph of partially hemolyzed primaquine-treated cells. After the incubation with primaquine, the cells were partially hemolyzed in an equal volume of $75 \mathrm{mM} \mathrm{NaCl}$ and then processed for sectioning. The cell and vacuolar membranes are intact. Membrane internalization is clearly seen by the continuity of the cell and vacuole membranes. The single arrow points to a cup-shaped indentation while the double arrow indicates a vacuole almost completely sealed off at its neck. Magnification $\times 26,000$.

with a continuity of the cell and vacuolar membranes (Fig. 2). Partial hemolysis per se did not induce vacuoles or cup-shaped deformities identifiable by electron microscopy.

Details and validation of the method. In preliminary experiments, we established that the ratio of cells to plasma and the preincubation time chosen, assured maximal coating of the cells by the $\mathrm{B}_{12}{ }^{57} \mathrm{Co}$ protein complex. The calcium concentration of the Hanks's solution $(1.25 \mathrm{~mm})$ was also adequate, and no further binding was achieved by increasing the calcium content of the system. The binding of the $\mathrm{B}_{12}{ }^{57} \mathrm{Co}$ protein complex by the erythrocytes was in the order of $1-2 \%$ of the added label. By varying the amount of added $B_{12-}$ ${ }^{57} \mathrm{Co}$ protein complex, it could be shown that there was a linear relationship between the bound radioactivity (i.e. the activity of washed, nontrypsinized cells) and the trapped radioactivity (i.e. the activity of washed and trypsinized cells). This observation permitted us to compare different experiments by correcting, when necessary, for differences in the degree of binding.

Validation of the isotopic method was achieved by parallel examination by two observers of the appearance of the erythrocytes under phase microscopy. In other experiments electron microscopy was performed by a third innocent observer who was asked to report on the presence or absence of vacuoles. Over 100 separate experiments have now been performed on red blood cells obtained from different donors and using different experimental conditions. Except for those experiments where binding of the $\mathrm{B}_{12}-{ }^{57} \mathrm{Co}$ protein complex to the cells was altered, there was invariable 
correlation between the semiquantitative estimate of the observers using either phase or electron microscopy and the isotopic radioactivity measurement.

Cells where vacuole formation was completely inhibited by prior metabolic depletion or low temperature incubation had the same low radioactivity as control cells not treated with vacuole-inducing agent. After vacuolated cells were hemolyzed in hypotonic solution, vacuoles persisted within the ghosts and about $60-70 \%$ of the radioactivity trapped in whole red cells was retained in the ghost fraction, showing that most of the radioactive label is membrane-bound. These observations, in addition to the electron microscopic demonstration that the intracellular vacuoles are lined by internalized plasma membrane (Fig. 2), allowed us to use the radioactive method as a direct measure of the internalized membrane area.

Phase microscopy is simple but cannot detect vacuoles smaller than the resolving power of the microscope. Electron microscopy can detect very small vacuoles but the technique is relatively cumbersome. Since both phase and electron microscopic examination give only semiquantitative data only the radioactivity measurements will be presented.

Dose, time, temperature, and $p H$ dependence. For the following experiments, and unless specified otherwise, primaquine was used as the vacuole-inducing agent. When plotted on semilogarithmic coordinates, there was a linear relation between primaquine concentration and membrane internalization up to a concentration of 2-2.25 mM (Fig. 3). Higher concentrations caused extensive hemolysis, thereby interfering with the assay. Vacuole formation was time-dependent and the higher the dose, the sooner a plateau phase was reached. At the adopted standard dose of $2 \mathrm{~mm}$ primaquine, the plateau phase was reached within 90-120 $\min$.

The optimal temperature for vacuole formation was around $37^{\circ} \mathrm{C}$, and no vacuoles were seen at temperatures lower than $23^{\circ} \mathrm{C}$. Vacuole formation was also reduced at temperatures above $45^{\circ} \mathrm{C}$. The $\mathrm{pH}$ dependence was measured by adjusting the $\mathrm{pH}$ of the final reaction mixture with dilute $\mathrm{HCl}$ or $\mathrm{NaOH}$ and measuring the final $\mathrm{pH}$ at the end of $2 \mathrm{hr}$. It was found that the optimum $\mathrm{pH}$ for vacuole formation was 7.9-8.1 and at $\mathrm{pH}$ 's below 6.4-6.5 vacuole formation was abolished.

Metabolic requirements. In view of the reported substrate requirement for the effect of primaquine on the osmotic fragility of red cells (25), experiments were designed to determine if vacuole formation was also energy-dependent.

Red cells were depleted of substrate by sterile incubation of whole blood at $37^{\circ} \mathrm{C}$, without additives, for

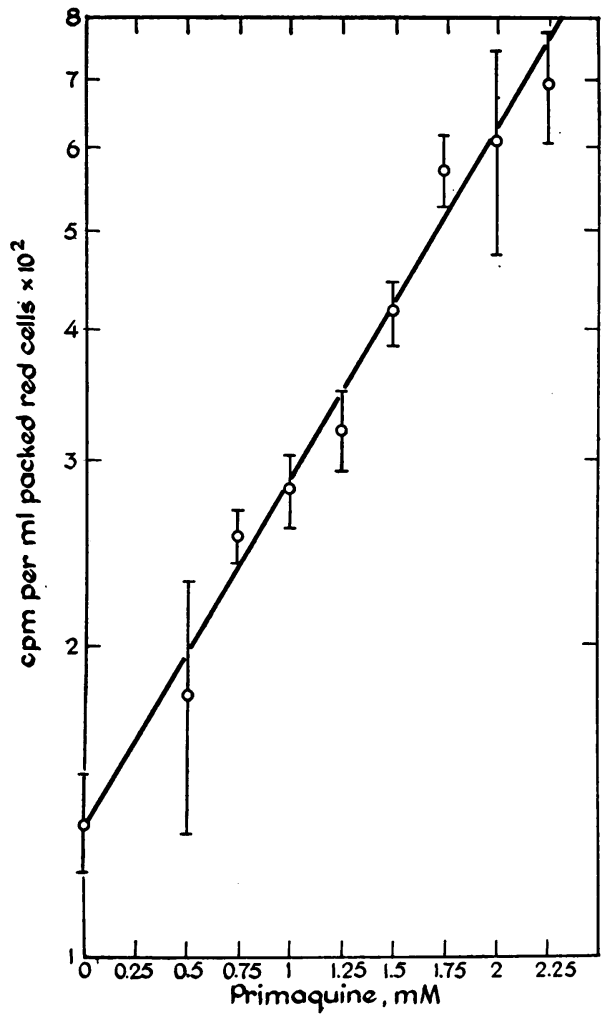

FIGURE 3 The effect of primaquine concentration on vacuole formation. Each point represents the mean \pm SD of 4-20 separate determinations.

$15 \mathrm{hr}$. After that, the cells were washed and samples were incubated for $2 \mathrm{hr}$ with 4 vol of $\mathrm{NaCl}$-phosphate buffer (9 parts $0.145 \mathrm{M} \mathrm{NaCl}$ and 1 part phosphate buffer $0.15 \mathrm{~m}, \mathrm{pH} 7.4$ ) and the various additives listed in Table I. The preincubation stage served to replenish the cells after which they were coated with the $\mathrm{B}_{12}{ }^{57} \mathrm{Co}$ protein complex and incubated with primaquine. As seen in the Table, depleted cells completely lost the ability to form vacuoles. This ability could be partially restored by inosine alone, but the best restoration was achieved by a combination of adenine and inosine.

The metabolic dependence of primaquine-induced vacuole formation was further studied in two experiments by comparing ATP levels in depleted and repleted red cells with their vacuole-forming capacity. In the single representative experiment shown in Table II, red cells were depleted by incubation at $37^{\circ} \mathrm{C}$ for $14 \mathrm{hr}$, but because particular care was taken to insure good mixing during the incubation, ATP levels were reasonably well maintained. After depletion, red cells were repleted by incubation for $2 \mathrm{hr}$ at $37^{\circ} \mathrm{C}$ with increasing concentrations of inosine as described in Table $I$ and the correlation between red cell ATP levels and vacuole formation is shown in Table II.

Erythrocyte Membrane Internalization 
The requirement of membrane internalization of an intact energy-producing pathway in the red cell could be demonstrated also by the use of the metabolic inhibitor, sodium fluoride. Cells preincubated with fluoride showed a dose-dependent decrease of vacuole formation (Fig. 4). At concentrations higher than 5$5.5 \mathrm{~mm}$, no vacuoles were seen.

In order to determine if in vivo aged red cells have adequate metabolic resources required for vacuole formation, $200 \mathrm{ml}$ of heparinized blood, freed from leucocytes by Ficoll sedimentation (Pharmacia Fine Chemicals Inc., Piscataway, N. J.), was ultracentrifuged for $1 \mathrm{hr}$ at $100,000 \mathrm{~g}$ at $4^{\circ} \mathrm{C}$. About $1 \%$ of the top, middle, and bottom fractions were collected, pooled, and processed as usual. Since the cells of the top fraction bind the $\mathrm{B}_{12}{ }^{57} \mathrm{Co}$ protein complex more avidly (17), results of vacuole formation were corrected to the same degree of binding. It was found that while the top and middle fractions had identical vacuole-forming ability, the bottom fraction was 16.5 and $14.7 \%$ less than the expected in two separate experiments.

The effect of the extracellular medium composition. Membrane internalization was equally well manifested in various buffers with different ionic compositions. Calcium was required for the binding of $\mathrm{B}_{12}{ }^{57} \mathrm{Co}$ protein complex to the red cells, but not for vacuole formation. Thus in the presence of chelators such as $\mathrm{Na}_{2}-$ EDTA vacuoles formed normally, as judged by direct phase microscopy observation. However, no binding of the complex occurred and no label was trapped in the vacuoles. In order to determine if the physiologic $\mathrm{Na}^{+}$, $\mathrm{K}^{+}$flux was required for vacuole formation, the effects of ouabain and nonionic and nonpenetrating electrolyte media were studied. Ouabain in concentrations up to $1.75 \mathrm{~mm}$ did not affect vacuole formation. On the

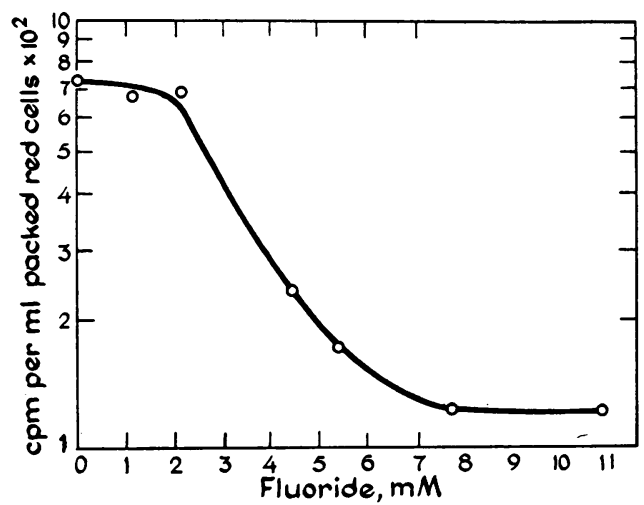

FIGURE 4 The effect of sodium fluoride on primaquine-induced vacuole formation. The cell mixtures were first preincubated with increasing concentrations of fluoride for 30 $\min$ at $37^{\circ} \mathrm{C}$, then primaquine, $2 \mathrm{~mm}$ was added and the incubation continued for another $2 \mathrm{hr}$. Each point represents the mean of three separate experiments.
TABLE I

Effects of Metabolic Depletion and Replenishment on Primaquine-Induced Vacuole Formation

\begin{tabular}{|c|c|c|}
\hline Cells & Substrate additive & $\begin{array}{c}\text { Vacuole } \\
\text { formation }\end{array}$ \\
\hline Fresh & 一 & 100 \\
\hline Depleted & - & 0 \\
\hline " & Glucose, $14 \mathrm{~mm}$ & 12 \\
\hline “ & Adenine, $1 \mathrm{~mm}$ & 8 \\
\hline “ & Inosine, $10 \mathrm{~mm}$ & 53 \\
\hline “ & Adenine, $1 \mathrm{~mm}+$ inosine, $10 \mathrm{~mm}$ & 57 \\
\hline “ & $\begin{array}{l}\text { Adenine, } 1 \mathrm{~mm}+\text { inosine, } \\
10 \mathrm{~mm}+\text { glucose, } 14 \mathrm{~mm}\end{array}$ & 68 \\
\hline “ & $\begin{array}{l}\text { Adenine, } 2 \mathrm{~mm}+\text { inosine, } \\
10 \mathrm{~mm}\end{array}$ & 68 \\
\hline “ & $\begin{array}{l}\text { Adenine, } 1 \mathrm{~mm}+\text { inosine, } \\
20 \mathrm{~mm}\end{array}$ & 67 \\
\hline
\end{tabular}

The depleted cells were preincubated with the various substrate additives for $2 \mathrm{hr}$. Then the fresh, depleted, and replenished cells, all from the same donor, were incubated with primaquine, $2 \mathrm{~mm}$ for $2 \mathrm{hr}$ at $37^{\circ} \mathrm{C}$. The results, which are the mean of two separate experiments, are expressed as percentage of the cpm trapped in the freshly drawn cells.

other hand, it was found that both nonionic solutes as sucrose and lactose, as well as a nonpenetrating electrolyte, sodium glutamate, caused about $50 \%$ reduction in membrane internalization. By adding increasing amounts of $\mathrm{NaCl}$, decreasing reductions in vacuole formation were obtained. In view of the report by Tsuboi and Fukunaga (26) that erythrocytes suspended in electrolyte or nonelectrolyte media of limited permeability have stimulated glycolytic rates and lower cellular ATP levels, we measured the ATP levels at the end of the $2 \mathrm{hr}$ incubation in two experiments and found that they were reduced to $40 \%$ of the control value. These results suggest that the reduction in membrane internalization observed in nonionic media could result from the lowering of the intracellular levels of ATP.

The effects of alteration of the red cell surface. Prior coating of $\mathrm{D}^{+}$red cells by a potent anti-D antiserum giving a strongly positive Coombs's reaction did not change vacuole formation. Neither did prior proteolytic digestion of the red cells for $30 \mathrm{~min}$ by trypsin or pronase both at a concentration of $1 \mathrm{mg} / \mathrm{ml}$. In the latter experiments vacuole formation could be assessed only by using phase microscopy since the proteolytic digestion destroyed the receptors for the $\mathrm{B}_{12}{ }^{15} \mathrm{Co}$ protein complex.

Sulfhydryl group blocking agents. Cellular and membrane sulfhydryl groups are known to be essential for the red cell integrity (27-29). The requirement of free sulfhydryl groups for vacuole formation was there- 
TABLE II

Relationship of ATP Levels in Erythrocytes and Vacuole Formation

\begin{tabular}{lcccc}
\hline & \multicolumn{2}{c}{ ATP* } & \\
\cline { 2 - 4 } & $\begin{array}{c}\text { Packed } \\
\text { RBC }\end{array}$ & $\begin{array}{c}\text { Value } \\
\text { of fresh } \\
\text { R BC }\end{array}$ & $\begin{array}{c}\text { Vacuole } \\
\text { formationt }\end{array}$ \\
\hline & $\mu$ moles/ml & $\%$ & \\
Fresh red blood cells & 0.57 & 100 & 100 \\
Depleted red blood cells & 0.35 & 61 & 44 \\
Red blood cells repleted with & & & \\
Glucose $14 \quad \mathrm{mM}$ & 0.37 & 65 & 46 \\
Inosine $\quad 0.10 \mathrm{mM}$ & 0.39 & 68 & 51 \\
Inosine & $1.0 \mathrm{mM}$ & 0.43 & 75 & 50 \\
Inosine & $5.0 \mathrm{mM}$ & 0.57 & 100 & 80 \\
\hline
\end{tabular}

* Measured after $2 \mathrm{hr}$ incubation at $37^{\circ} \mathrm{C}$ with $2 \mathrm{~mm}$ primaquine.

¥ Vacuole formation of freshly drawn RBC was arbitrarily set at 100 and the corresponding values of the depleted and replenished cells were adjusted accordingly.

fore studied using two sulfhydryl reacting agents: the freely permeable $\mathrm{N}$-ethylmaleimide $(\mathrm{NEM})^{1}$ and the slowly penetrating $p$-hydroxymercuriphenyl sulfonate (PHMPS) (27-30). Both agents were found to block vacuole formation in a dose-related manner as can be seen in Fig. $5 a$ and $b$. In the case of NEM, measurements of vacuole formation and red cell GSH levels were made in parallel. It can be seen that only at concentrations of NEM above those required to deplete completely free intracellular GSH, was vacuole formation affected.

The effect of hydrocortisone, chlorpromazine, and vinblastine. Hydrocortisone and chlorpromazine were chosen for a study of their effects on primaquine-induced membrane internalization because of the reports that these agents stabilized erythrocyte membranes (31, 32). Vinblastine was also' studied because it binds to erythrocyte membrane proteins resulting in their aggregation and precipitation (33). Therefore, it was surprising to find that none of these agents protected or stabilized the membrane. On the contrary, at low doses they markedly enhanced the primaquine effect and at higher dosage they alone could induce the same membrane internalization as did primaquine. The enhancement by these agents of the effect of a low dose of primaquine $(1 \mathrm{~mm})$ is demonstrated graphically in Fig. 6. The concentration of these drugs which sufficed to produce membrane internalization when added alone were: $10 \mathrm{~mm}$ hydrocortisone, $0.4 \mathrm{~mm}$ vinblastine, and $0.3 \mathrm{~mm}$ chlorpromazine. Vacuole formation by

\footnotetext{
${ }^{1}$ Abbreviations used in this paper: NEM, $N$-ethylmaleimide; PHMPS, p-hydroxymercuriphenyl sulfonate.
}

these agents could be blocked by prior substrate depletion of the erythrocytes or by fluoride at the same dosages which inhibited primaquine-induced vacuole formation (Table III). Similarly to their enhancing effect with primaquine, these three drugs when combined greatly enhanced the vacucle-forming effects of each other.

The structure of the 8-aminoquinolines and vacuoleforming capacity. Although it was clear from the previous study that several membrane-active compounds of diverse chemical structure have the ability to induce internalization of the red cell membrane, the availability of many 8-aminoquinoline analogs affords an opportunity to study the structural requirements for vacuole formation and to compare them to their known antiplasmodial activities. Several 6-mexthoxy-8-aminoquinolines differing in the aliphatic side-chain like pamaquine, pentaquine, isopentaquine, and the straightchain analog of pamaquine, 8-[5-(diethylamino)-pentyl

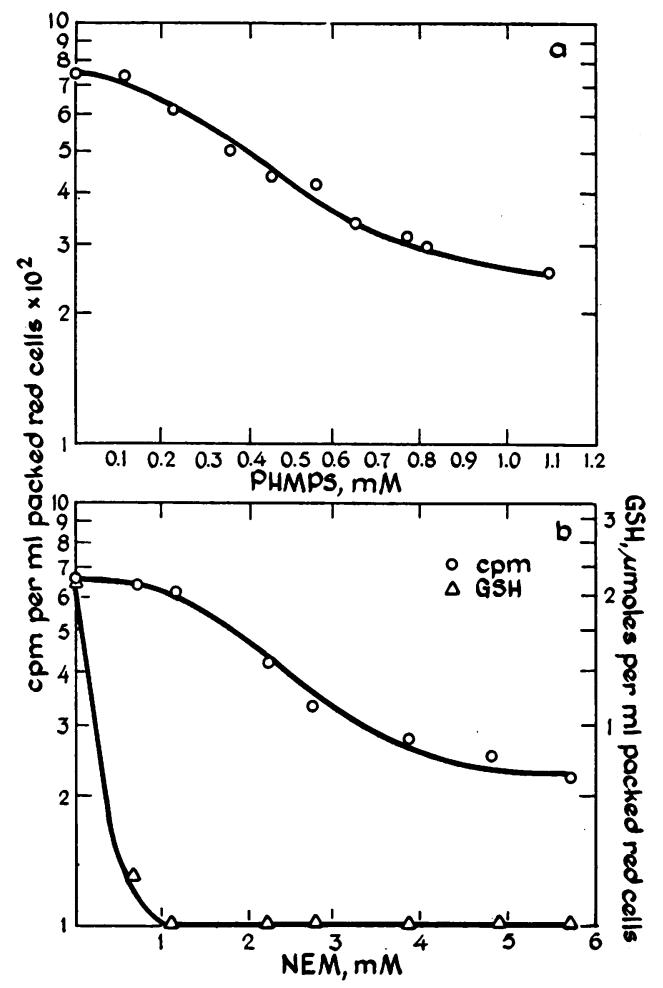

FIGURE 5 The effect of PHMPS and NEM on primaquineinduced vacuole formation and GSH levels. The cell mixtures were first preincubated with increasing concentrations of PHMPS (a) or NEM $(b)$ for $30 \mathrm{~min}$ at $37^{\circ} \mathrm{C}$, then primaquine, $2 \mathrm{~mm}$ was added and the incubation continued for another $2 \mathrm{hr}$. Each point represents the mean of three separate experiments. In the case of NEM-treated cells, parallel samples were washed at the end of the incubation to remove excess NEM, and assayed for GSH. The GSH values are given on the right ordinate of $5 b$. 


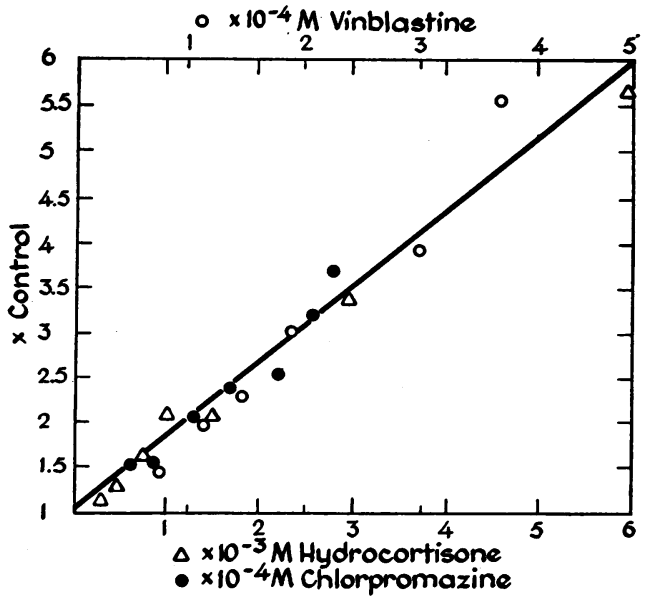

Figure 6 The effects of hydrocortisone, vinblastine, and chlorpromazine on primaquine-induced vacuole formation. The cell mixtures were preincubated with varying concentrations of the three drugs for $30 \mathrm{~min}$ at $37^{\circ} \mathrm{C}$, then primaquine, $1 \mathrm{~mm}$ was added and the incubation continued for another $2 \mathrm{hr}$. The results are expressed as the multiples of the value of cells treated with primaquine, $1 \mathrm{~mm}$ alone. The upper abscissa corresponds to $10^{-4} \mathrm{M}$ vinblastine and the lower abscissa to $10^{-3} \mathrm{M}$ hydrocortisone and $10^{-4} \mathrm{M}$ chlorpromazine.

amino]-6-methoxy aminoquinoline, were as active as primaquine in vacuole formation. These compounds differ also in their terminal amino which is primary in primaquine, secondary in pentaquine and isopentaquine, and tertiary in pamaquine and its analog. Analogs without the terminal alkylamino group were inactive. The importance of the 5- and 6-position substitutions is shown in Table IV, where it can be seen that substitution of the hydrogen in position 5 markedly reduces, if not abolishes, the vauole-forming activity. Since the 5,6-dihydroxy derivative has the highest antiplasmodial activity (34), it is clear that vacuole-forming capacity is separate and distinct from other properties of the 8-aminoquinolines.

TABLE III

The Effect of Substrate Depletion and Fluoride on Drug-Induced Vacuole Formation

\begin{tabular}{lrrr}
\hline \multirow{2}{*}{ Cells } & \multicolumn{3}{c}{ Vacuole formation } \\
\cline { 2 - 4 } & $\begin{array}{c}\text { Hydro- } \\
\text { cortisone, } \\
15 \mathrm{mM}\end{array}$ & $\begin{array}{c}\text { Vin- } \\
\text { blastine, } \\
0.9 \mathrm{mM}\end{array}$ & $\begin{array}{c}\text { Chlor- } \\
\text { promazine, } \\
0.7 \mathrm{mM}\end{array}$ \\
\hline Control & 100 & 100 & 100 \\
Substrate-depleted (1) & 0 & 2 & 3 \\
Sodium fluoride, 11 mM (3) & 3 & 3 & 12 \\
\hline
\end{tabular}

The results are expressed as the mean of the percentage of cpm trapped in the control cells. Number of experiments is given in parenthesis.
TABLE IV

The Relative Vacuole-Forming Capacity and Antiplasmodial Activity of Pentaquine Analogs

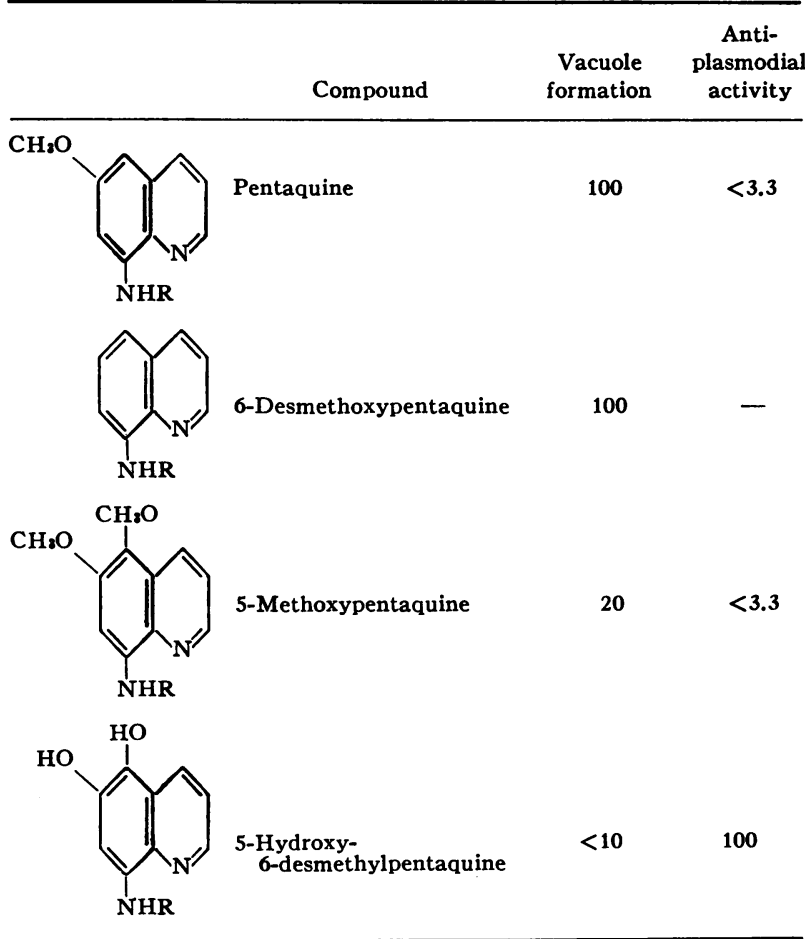

$\mathrm{R}=-\left(\mathrm{CH}_{2}\right)_{8} \mathrm{NHCH}\left(\mathrm{CH}_{2}\right)_{2}$

All drugs were tested in a final concentration of $2 \mathrm{~mm}$. The relative antiplasmodial in vitro activites were calculated from the data of Greenberg, Taylor, and Josephson (34).

Mechanism of drug action. The implicit assumption made on the basis of metabolic and inhibitor studies, as well as the studies with membrane-active drugs is that the drugs induce vacuole formation. It is, however, also possible that vacuoles are being continuously formed as a consequence of essentially normal membrane processes and that the drugs tested act simply by stabilizing and accumulating vacuoles thus formed. The latter alternative was explored by addition of the bifunctional chemical fixative glutaraldehyde, at various times during the incubation procedure. Concentrations of $0.05-0.5 \%$ glutaraldehyde produce equivalent fixation by cross-linking of membrane and intracellular proteins (35). Presumably because of this cross-linking action, concentrations of buffered glutaraldehyde prepared as described by Ham, Dunn, Sayre, and Murphy (35) in excess of $0.03 \%$, fixed the vitamin $\mathrm{B}_{12}$-protein complex to the red cell membrane so that it could not be removed by washing and trypsinization. Therefore, glutaraldehyde was tested at two concentrations, 0.03 and $0.2 \%$, but at the higher concentration, vacuole formation was monitored by phase microscopy alone, while at the lower 
concentration, the isotopic method could be used as well. The addition of glutaraldehyde to fresh red cells incubated without drugs in the last $30 \mathrm{~min}$ of the $2 \mathrm{hr}$ incubation produced no discernable vacuoles with either concentration. Addition of glutaraldehyde at the beginning of the incubation produced no vacuoles with the higher concentration, while a rare vacuole, not significantly different from the Hanks's solution-incubated control, was seen with the $0.03 \%$ concentration. The isotopic measurements for the latter experiment were: Hanks's solution control, $40 \mathrm{cpm} / \mathrm{ml}$ red blood cells; glutaraldehyde $0.03 \%, 62 \mathrm{cpm} / \mathrm{ml}$ red blood cells; and $2 \mathrm{~mm}$ primaquine, $409 \mathrm{cpm} / \mathrm{ml}$ red blood cells. Addition of $0.03 \%$ glutaraldehyde to a tube containing $1.5 \mathrm{~mm}$ primaquine did not alter isotopic trapping, the values being: $40 \mathrm{cpm} / \mathrm{ml}$ red blood cells for the saline control, $260 \mathrm{cpm} / \mathrm{ml}$ red blood cells for $1.5 \mathrm{~mm}$ primaquine, and $302 \mathrm{cpm} / \mathrm{ml}$ red blood cells for the reaction mixture containing $1.5 \mathrm{~mm}$ primaquine and $0.03 \%$ glutaraldehyde. Addition of $0.2 \%$ glutaraldehyde blocked vacuole formation in the primaquine-containing tubes.

Membrane internalization in resealed ghosts. In attempting to understand the mechanisms of vacuole formation, we turned to a more defined system. Penniston and Green had reported that red cell ghosts energized by ATP underwent shape changes which corresponded to pinocytosis or vacuole formation (36). In view of the similarity between this phenomenon and the drug-induced vacuole formation in whole red cells, we decided to study the resealed ghost preparation.

TABLE V

The Effects of Calcium, Magnesium, Inhibitors, and Primaquine on Membrane Internalization of Resealed Ghosts

\begin{tabular}{lc}
\multicolumn{1}{c}{ Ghosts } & Vacuole formation \\
\hline A. Control & 100 \\
$\mathrm{No}^{++} \mathrm{Mg}^{++} \mathrm{TP}$ & $0 \pm 2$ \\
${\mathrm{No} \mathrm{Mg}^{++}}^{\mathrm{CaCl}}, 10 \mathrm{mM}$ & $10 \pm 2$ \\
& $35 \pm 11$ \\
B. Sodium fluoride, $11 \mathrm{mM}$ & $18 \pm 10$ \\
NEM, 3 mM & $14 \pm 2$ \\
PHMPS, $1 \mathrm{mM}$ & $124 \pm 19$ \\
Primaquine, $2 \mathrm{mM}$ & $94 \pm 11$ \\
\hline
\end{tabular}

The control ghosts were hemolyzed with 10 vol of Na-ATP, $10 \mathrm{~mm}$ and resealed with a salt solution so that the final concentrations were: $154 \mathrm{mM} \mathrm{KCl}, 10 \mathrm{mM} \mathrm{MgCl}_{2}$, and $2.5 \mathrm{mM}$ $\mathrm{CaCl}_{2}$. In $\mathrm{A}$, the various additions or delections were made during the resealing stage. In $B$, the various additions were to the final mixtures. All results are expressed as the mean \pm SD of the percentage of $\mathrm{cpm}$ of the control in three separate experiments.

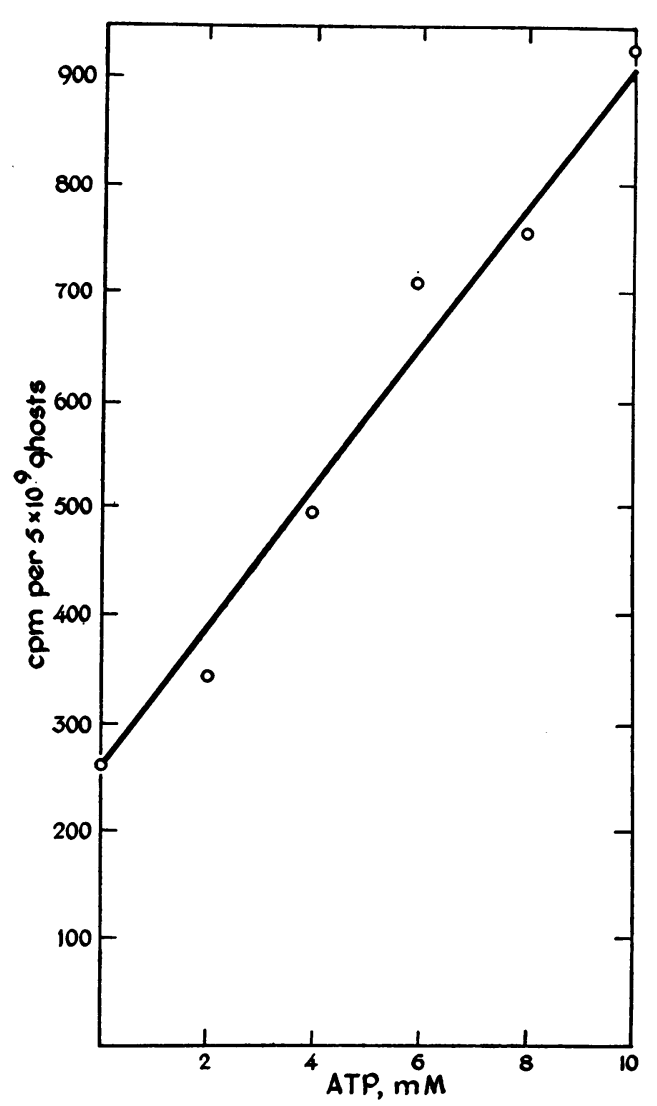

Figure 7 The effect of the ATP concentration of the hemolyzing solution on membrane internalization of resealed ghosts. ATP concentration is recorded on the abscissa and trapping of isotopic activity in vacuoles is recorded on the ordinate.

In preliminary studies, we established the validity of the radioactive method with the partially hemolyzed resealed ghosts. In confirmation of Penniston and Green's work, we found that ATP was absolutely required for the vacuole formation. There was a linear relationship between the degree of membrane internalization and the concentration of ATP in the hemolyzing solution (Fig. 7). Moreover, the active agent was probably $\mathrm{Mg}^{++}$-ATP since the omission of magnesium from the resealing solution completely abolished membrane internalization. On the other hand, calcium ions were inhibitory for membrane internalization and at a concentration above $10 \mathrm{mM} \mathrm{CaCl}$, membrane internalization was significantly reduced and was completely blocked by $\mathrm{CaCl}_{2}$ at the concentration of $20 \mathrm{~mm}$. $\mathrm{Na}_{2}-$ EDTA alone could not induce membrane internalization in the absence of $\mathrm{Mg}^{++}$-ATP. Addition of glutaraldehyde at a concentration of $0.03 \%$ completely blocked vacuole formation induced by resealing with $10 \mathrm{~mm}$ $\mathrm{Mg}^{++}$-ATP.

Erythrocyte Membrane Internalization 
In attempting to determine if the whole red cell and the ghost membrane internalization reflected the same basic phenomenon, the effects of the vacuole-inducing drugs and the various inhibitors were tested on the resealed ghosts. Addition of primaquine or any of the other agents active on whole red cells, did not increase membrane internalization above that caused by various concentrations of $\mathrm{Mg}^{++}$-ATP alone. PHMPS did not inhibit the $\mathrm{Mg}^{++}$-ATP-induced vacuole formation in the ghosts. On the other hand, NEM inhibited internalization in whole red blood cells and in resealed ghosts. Fluoride inhibited the $\mathrm{Mg}^{++}$-ATP ghost membrane internalization probably due to complex formation with magnesium and this could be partially reversed by increasing the concentration of $\mathrm{MgCl}_{2}$ used in the resealing step. These results are summarized in Table V.

\section{DISCUSSION}

Ginn et al. first demonstrated that intraerythrocytic vacuole formation could be induced by primaquine and proposed that the mechanism of vacuole formation involved membrane internalization (16).

In addition to morphologic examination, this phenomenon has been studied indirectly by measuring changes in osmotic fragility (25). The increases in osmotic fragility observed probably reflect the overall loss of membrane surface produced by internalization. However, this method has many limitations and is less useful than a direct measurement of the internalized surface membrane. The method described here is simple and is capable of providing accurate quantitative data. By use of this method, we found that several 8-aminoquinolines, in addition to primaquine, induce membrane internalization. In extending these studies, we focussed on a class of drugs that Seeman has identified as being membrane-active $(31,32)$. Most have a biphasic effect on red cell membranes. Low, prehemolytic concentrations seem to stabilize membranes against hypotonic hemolysis, probably through expansion of the membrane, while higher concentrations cause hemolysis (32). Of these membrane-active drugs, chlorpromazine and hydrocortisone, as well as vinblastine, were studied and found to induce vacuoles in a manner identical to that of primaquine. That this is not a very general phenomenon of drug action on red cell membranes is indicated by the results obtained with the 8-aminoquinoline analogs, wherein specific side group substitution resulted in loss of vacuole-forming capacity. The studies with glutaraldehyde also indicated that the drugs were instrumental in vacuole formation and did not act by simply stabilizing and allowing vacuoles to accumulate.

The dependence of vacuole formation on active en- ergy-producing metabolism, with $\mathrm{pH}$ and temperature optima paralleling those of red cell glycolysis (37), indicates that this phenomenon is not simply a physicochemical effect of drugs possessing detergent-like properties. The data supporting energy requirement include the observation that prior metabolic depletion results in loss of vacuole formation. Vacuole formation in depleted cells could be partially restored by replenishment with adenine and inosine (Table I), a combination which has been shown to restore intracellular ATP levels of stored cells (38). Correlation of ATP levels with vacuole-forming capacity was also indicated by the repletion studies as shown in Table II. Sodium fluoride, a glycolytic inhibitor also blocked vacuole formation by all four agents tested. The reduction of primaquine-induced vacuole formation of cells suspended in nonionic or nonpenetrating electrolyte media closely paralleled the reduction of the ATP level in these cells. Our results therefore support the metabolic requirements observed by George, O'Brien, Pollack, and Crosby (25) who proposed that the energy was used for the biotransformation of primaquine to an active metabolite, possibly a hydroxylated one. However, the supposedly active hydroxylated metabolite, the 5,6-dihydroxy derivative of pentaquine, has essentially no vacuole-forming capacity (Table IV). More importantly, our studies show that energy, perhaps in the form of ATP specifically, is required for the process of membrane internalization itself as mediated by the four agents tested.

The role of either red cell glutathione or membrane sulfhydryl groups in membrane internalization was tested (39). NEM blocked vacuole formation only at concentrations which were well above those required for complete inhibition of the intracellular GSH (Fig. $5 b)$ and at levels which are inhibitory for intracellular glycolytic enzymes and membrane sulfhydryl groups (27). The requirement for free membrane sulfhydryl groups is demonstrated by the inhibition of vacuole formation caused by PHMPS, a poorly penetrating inhibitor which, like $p$-mercuribenzoate, has little effect on intracellular sulfhydryl groups and glycolysis (27).

In order to study the events leading to membrane internalization more definitely the resealed ghost preparation was used because the process of membrane internalization in energized ghosts (36) is similar to vacuole formation in whole red cells both morphologically and by its dependence on a high energy source like ATP. Nevertheless, differences between vacuole formation in whole red blood cells and ghosts are indicated by the lack of inhibition of ghost membrane internalization by PHMPS (Table V) and the inability of the membrane-active drugs to increase membrane internalization in energized ghosts. However, there is evidence 
suggesting that molecular rearrangement occurs during hemolysis $(40,41)$, and it is therefore possible that such membrane rearrangement would account for the lack of the effect of PHMPS and the membrane-active drugs on the ghosts. Another possible explanation for the differences is that in whole red cells, PHMPS and the membrane-active drugs may be involved in steps leading to the approach and energization of the membrane by ATP while this step is already accomplished in the resealed ghost preparation.

We cannot offer an explanation for all our data, however, our observations can be considered on the basis of the known interrelations of $\mathrm{Ca}^{++}, \mathrm{Mg}^{++}$, ATP, and erythrocyte deformability. Weed, LaCelle, and Merrill, and Weed and LaCelle, have presented data which indicate that red cell membrane deformability is dependent on a balance between the internal concentration of $\mathrm{Ca}^{++}, \mathrm{Mg}^{++}$, and ATP, where ATP and $\mathrm{Mg}^{++}$ enhance deformability while calcium causes rigidity of the membrane $(8,9)$. Chlorpromazine $(42)$ and vinblastine (33) are known to compete with calcium for the same sites on membrane proteins. It has also been shown that many of the membrane-active drugs displace calcium from artificial membranes (see 42 for references). One can speculate that membrane internalization will occur in red cells if the balance between magnesium and ATP on one hand, and calcium on the other, is shifted by drugs which displace calcium from the membrane allowing $\mathrm{Mg}^{++}$-ATP to approach and energize the membrane. Metabolic depletion will prevent the drug-induced membrane internalization by lowering the ATP levels and increasing the intracellular calcium concentration $(8,43)$. This interpretation is supported by the effects of these three components in the ghost preparation where $\mathrm{Mg}^{++}$-ATP causes membrane internalization and calcium blocks it.

While there are the above noted similarities between the determinants of ghost membrane deformability ( 8 , 9 ) and the phenomenon of membrane internalization in resealed ghosts, there are some important differences. $\mathrm{Mg}^{++}$alone or ATP alone can restore deformability to depleted ghosts, but a combination of $\mathrm{Mg}^{++}$and ATP is required for membrane internalization. EDTA alone can restore deformability to ghosts but produces no membrane internalization. These findings suggest that the critical issue in ghost deformability is $\mathrm{Ca}^{++}$chelation while energizing of the membrane by $\mathrm{Mg}^{++}$-ATP is critical for membrane internalization.

Another major issue is whether or not the in vitro phenomena presented here are in any way relevant to physiologic events. Except for the pinocytosis observed in neonatal red cells, especially when coated with antibodies $(10,11)$, similar membrane internalization has not been observed in circulating erythrocytes in adults.
The postsplenectomy vacuoles, which have a limiting membrane identical to the plasma membrane, could arise by a process of membrane internalization, but there is no clear evidence for this. Similarly the reported selective loss of surface area of stress reticulocytes during their maturation (44) could be achieved either by external fragmentation or by membrane internalization with pitting by the spleen of the resulting vacuoles. Moreover, it can be speculated that membrane internalization continues beyond the stage of the reticulocyte and is a continually ongoing process by which the cells lose surface membrane, thus becoming more spheroidal as they age. This process of membrane internalization would be masked by the normal pitting function of the spleen (45-47), but in the absence of the spleen vacuoles become apparent.

We believe that the data presented provide a basis for considering and testing a concept of the mechanism of action of an entire group of membrane-active drugs. These studies also confirm the interrelationship between erythrocytic metabolism and surface-related phenomena and in particular indicate that rather moderate alterations in metabolism can produce easily detectable alterations in membrane-related events.

\section{ACKNOWLEDGMENTS}

We are grateful to Colonel William E. Rothe, Director, Medicinal Chemistry Division, Walter Reed Army Institute of Research for the supply of the 8-aminoquinoline analogs.

This work was supported by U. S. Public Health Service grants R1-AM 13682 and GM 16445.

\section{REFERENCES}

1. Jandl, J. H. 1965. Leaky red cells. An analytical review. Blood. 26: 367.

2. Weed, R. I., and C. F. Reed. 1966. Membrane alterations leading to red cell destruction. Amer. J. Med. 41: 681.

3. Weed, R. I. 1970. Disorders of red cell membrane: history and perspectives. Semin. Hematol. 7: 249.

4. LaCelle, P. L. 1970. Alteration of membrane deformability in hemolytic anemias. Semin. Hematol. 7: 335.

5. Nakao, M., T. Nakao, M. Tatibana, H. Yoshikawa, and T. Abe. 1959. Effect of inosine and adenine on adenosine triphosphate regeneration and shape transformation in long-stored erythrocytes. Biochim. Biophys. Acta. 32: 564 .

6. Nakao, M., T. Nakao, and S. Yamazoe. 1960. Adenosine triphosphate and maintenance of shape of the human red cells. Nature (London). 187: 945.

7. Weed, R. I., and A. J. Bowdler. 1966. Metabolic dependence of the critical hemolytic volume of human erythrocytes. Relationship to osmotic fragility and autohemolysis in hereditary spherocytosis and normal red cells. J. Clin. Invest. 45: 1137.

8. Weed R. I., P. L. LaCelle, and E. W. Merrill. 1969. Metabolic dependence of red cell deformability. J. Clin. Invest. 48: 795. 
9. Weed, R. I., and P. L. LaCelle. 1969. ATP dependence of erythrocyte membrane deformability. Relation to "in vivo" survival and blood storage. In Red Cell Membrane. Structure \& Function. G. A. Jamieson and T. J. Greenwalt, editors. J. B. Lippincott Company, Philadelphia. 1 : 318.

10. Blanton, P. L., J. Martin, and S. Haberman. 1968. Pinocytotic response of circulating erythrocytes to specific blood grouping antibodies. J. Cell Biol. 37: 716.

11. Voak, D., and M. A. Williams. 1971. An explanation of the failure of the direct antiglobulin test to detect erythrocyte sensitization in ABO haemolytic disease of the newborn and observations on pinocytosis of $\mathrm{IgG}$ anti-A antibodies by infant (cord) red cells. Brit. J. Haematol. 20: 9.

12. Holroyde, C. P., F. A. Oski, and F. H. Gardner. 1969. The "pocked" erythrocyte. N. Engl. J. Med. 281: 516.

13. Koyama, S., H. Kihira, S. Aoki, and H. Ohnishi. 1962. Postsplenectomy vacuole, new erythrocyte inclusion body. Mie Med. J. 11 : 425.

14. Kent G., O. T. Minick, F. I. Volini, and E. Orfei. 1966. Autophagic vacuoles in human red cells. Amer. J. Pathol. 48: 831.

15. Holroyde, C. P., and F. H. Gardner. 1970. Acquisition of autophagic vacuoles by human erythrocytes. Physiological role of the spleen. Blood. 36: 566.

16. Ginn, F. L., P. Hochstein, and B. F. Trump. 1969 Membrane alterations in hemolysis: internationalization of plasmalemma induced by primaquine. Science (Washington). $164: 843$.

17. Retief, F. P., C. W. Gottlieb, and V. Herbert. 1966. Mechanism of vitamin $B_{12}$ uptake by erythrocytes. $J$. Clin. Invest. 45 : 1907.

18. Hoffman, J. F., D. C. Tosteson, and R. Whittam. 1960. Retention of potassium by human erythrocyte ghosts. Nature (London). 185 : 186.

19. Schrier, S. L. 1967. ATP synthesis in human erythrocyte membranes. Biochim. Biophys. Acta. 135: 591.

20. Beutler, E., O. Duron, and B. M. Kelly. 1963. Improved method for the determination of blood glutathione. $J$. Lab. Clin. Med. $61: 882$.

21. Sabatini, D. D., K. G. Bensch, and R. J. Barrnett. 1963. Cytochemistry and electron microscopy. The preservation of cellular ultrastructure and enzymatic activity by aldehyde fixation. J. Cell Biol. 17: 19.

22. Palade. G. E. 1952. A study of fixation for electron microscopy. J. Exp. Med. 95: 285.

23. Freeman, J. A., and B. O. Spurlock. 1962. A new epoxy embedment for electron microscopy. J. Cell Biol. 13: 437.

24. Venable, J. H., and R. Coggeshall. 1965. A simplified lead citrate stain for use in electron microscopy. $J$. Cell Biol. 25 : 407.

25. George, J. N., R. L. O'Brien, S. Pollack, and W. H. Crosby. 1966. Studies of in vitro primaquine hemolysis: substrate requirement for erythrocyte membrane damage. J. Clin. Invest. 45: 1280.

26. Tsuboi, K. K., and K. Fukunaga. 1970. Relationship of solute permeability to erythrocyte glycolysis. Biochim. Biophys. Acta. 196: 215.

27. Jacob, H. S., and J. H. Jandl. 1962. Effects of sulfhydryl inhibition on red cells. I. Mechanism of hemolysis. J. Clin. Invest. $41: 779$.

28. Jacob, H. S., and J. H. Jandl. 1962. Effects of sulfhydryl inhibition on red blood cells. II. Studies in vivo. J. Clin. Invest. 41 : 1514.
29. Rega, A. F., A. Rothstein, and R. I. Weed. 1967. Erythrocyte membrane sulfhydryl groups and the active transport of cations. J. Cell. Physiol. 70: 45.

30. Shapiro, B., G. Kollmann, and D. Martin. 1970. The diversity of sulfhydryl groups in the human erythrocyte membrane. J. Cell. Physiol. $75: 281$.

31. Seeman, P. 1966. Erythrocyte membrane stabilization by steroids and alcohols; a possible model for anesthesia. Biochem. Pharmacol. $15: 1632$.

32. Seeman, P. 1966. II. Erythrocyte membrane stabilization by local anesthetics and tranquilizers. Biochem. Pharmacol. 15 : 1753.

33. Wilson, L., J. Bryan, A. Ruby, and D. Mazia. 1970. Precipitation of proteins by vinblastine and calcium ions. Proc. Nat. Acad. Sci. U. S. A. 66: 807.

34. Greenberg, J., O. J. Taylor and E. S. Josephson. 1951. Studies on Plasmodium gallinaceum in vitro. II. The effects of some 8-aminoquinolines against the erythrocytic parasites. J. Infect. Dis. 88: 163.

35. Ham, T. H., R. F. Dunn, R. W. Sayre, and J. R. Murphy. 1968. Physical properties of red cells as related to effects in vivo. I. Increased rigidity of erythrocytes as measured by viscosity of cells altered by chemical fixation, sickling and hypertonicity. Blood. 32: 847.

36. Penniston, J. T., and D. E. Green. 1968. The conformational basis of energy transformations in membrane systems. IV. Energized state and pinocytosis in erythrocyte ghosts. Arch. Biochem. Biophys. 128: 339.

37. Chapman, R. G., M. A. Hennessey, A. M. Waltersdorph, F. M. Huennekens, and B. W. Gabrio. 1962. Erythrocyte metabolism. V. Levels of glycolytic enzymes and regulation of glycolysis. J. Clin. Invest. 41: 1249.

38. Simon, E. R. 1967. Adenine and purine nucleosides in human red cell preservation: a review. Transfusion (Philadelphia) . $7: 395$.

39. Jacob, H. S. 1970. Mechanisms of Heinz body formation and attachment to red cell membrane. Semin. Hematol. $7: 341$.

40. Wittels, B., and P. Hochstein. 1966. The effect of primaquine on lecithin metabolism in human erythrocytes. Biochim. Biophys. Acta. 125: 594.

41. Wittels, B. 1970. Modification of phospholipid metabolism in human red cells by primaquine. A possible mechanism in drug-induced hemolysis. Biochim. Biophys. Acta. 210: 74.

42. Kwant, W. O., and P. Seeman. 1969. The displacement of membrane calcium by a local anesthetic (chlorpromazine). Biochim. Biophys. Acta. 193: 338.

43. Lew, W. L. 1969. On the ATP dependence of the $\mathrm{Ca}^{2+}$ induced increase in $\mathrm{K}^{+}$permeability observed in human red cells. Biochim. Biophys. Acta. 193: 338.

44. Come, S. E., S. B. Shohet, and S. H. Robinson. 1971. Fate of stress reticulocytes: Hemolysis or fragmentation? J. Clin. Invest. 50: 21a. (Abstr.)

45. Crosby, W. H. 1959. Normal function of the spleen relative to red blood cells. A review. Blood. 14: 399.

46. Koyama, S., S. Aoki, and K. Deguchi. 1964. Electron microscopic observations of the splenic pulp with special reference to the pitting function. Mie Med. J. 14: 143.

47. Rifkind, R. A. 1966. Destruction of injured red cells in vivo. Amer. J. Med. $41: 711$. 